\title{
Robótica Educacional: A Possibilidade de múltiplas aprendizagens no espaço escolar.
}

\author{
Braun, Julio César \\ UNIOESTE \\ Toledo, Brasil \\ juliocbraun@gmail.com
}

\begin{abstract}
This work aims to promote the discussion about the possibility of learning in multiple areas of knowledge using Educational Robotics as a tool in the regular learning teaching process. Based on Piaget's concepts, Papert's technological learning theory and the methodological guidelines of the National Common Curricular Base, as well as the constituent elements of daily practice and pedagogical learning experiences that took place in the Pilot Project of Educational Robotics implemented at the Anita Garibaldi Municipal School at Toledo - Pr in the years 2018 and 2019. As a result, it was intended to describe some relevant considerations about the students' immersion experience in the field of Educational Robotics and the contributions to the educational mediation process.
\end{abstract}

Resumo - Este trabalho tem por objetivo promover a discussão sobre a possibilidade da aprendizagem nas múltiplas áreas do conhecimento utilizando a Robótica Educacional como ferramenta no processo de ensino aprendizagem formal. Pautado nos conceitos Piagetianos, na teoria tecnológica de aprendizagem de Papert e nas orientações metodológicas da Base Nacional Curricular Comum, como também aos elementos constitutivos da prática cotidiana e das experiências pedagógicas de aprendizagem ocorridas no Projeto Piloto de Robótica Educacional implementado na Escola Municipal Anita Garibaldi Município de Toledo - Pr nos anos de 2018 e 2019. Como resultado descreve-se algumas considerações relevantes sobre experiência de imersão dos alunos no campo da Robótica Educacional e as contribuições no processo de mediação educativa.

Palavras-chave - Robótica; Aprendizagem; Educação.

\section{INTRODUÇÃO}

A tecnologia tornou-se uma ferramenta presente na vida social, com a evolução da comunicação imprimiu-se uma nova rotina no relacionamento das pessoas, porém, apesar da grande velocidade que a tecnologia digital avança, à Escola enquanto instituição social de desenvolvimento da aprendizagem e de acesso ao conhecimento sistematizado caminha a passos lentos. A implementação de ferramentas tecnológicas para desenvolvimento da aprendizagem muitas vezes não se efetiva na prática ou são pouco utilizadas a favor da promoção e produção de conhecimento escolar.

Contudo desde 1980, o professor Seymour Papert, um grande teórico da inteligência artificial discutia a utilização da tecnologia aplicada a Educação como ferramenta de produção do conhecimento escolar. Influenciado por educadores como Jean Piaget, Lev Vygotsky, Montessori, John Dewey e Paulo Freire, Papert utilizou das teorias do construtivismo e interacionismo para criar sua própria teoria de aprendizagem, o construcionismo ${ }^{1}$.

Levando em consideração o contexto tecnológico da sociedade atual e os estudos de Papert, realizou-se um estudo metodológico priorizando a utilização da tecnologia digital no processo de ensino-aprendizagem, em específico tratou-se neste artigo da experiência de Robótica Educacional como ferramenta de múltiplas aprendizagens na ação educativa da Escola Municipal Anita Garibaldi (EMAG) Toledo - PR, nos anos de 2018 e 2019.

Em síntese este trabalho objetiva elencar alguns elementos fundamentais e aspectos pedagógicos presentes nas aulas de Robótica Educacional e as experiências positivas de acesso ao mundo digital e as contribuições deste elemento na efetivação da aprendizagem nas múltiplas áreas do conhecimento escolar. A Educação formal é um espaço de disseminação do conhecimento acumulado pela sociedade, estes conhecimentos expressão a evolução histórica do homem. A Escola torna-se neste sentido um espaço de mediação do conhecimento acumulado, língua portuguesa, matemática, história, geografia, ciências entre outros que fazem parte dos currículos escolares. Paralelo a esse universo a efetivação da aprendizagem nas Escolas exige do professor pesquisa e conhecimento de metodologias que possam atingir o aluno e proporcionar um contexto de assimilação e aprendizagem dos conteúdos. Deste modo, instrumentos, métodos e avaliação estão em constante discussão para garantir o sucesso no processo de ensino/aprendizagem. Os estudos teóricos e pedagógicos investigam essencialmente como a aprendizagem ocorre com o aluno, assim como a diversidade e possibilidades de métodos que este aluno necessita para compreender 0 processo de ensino/aprendizagem. Para cada aluno deve-se proporcionar elementos metodológicos que efetivamente possam dar acesso ao desenvolvimento cognitivo nas

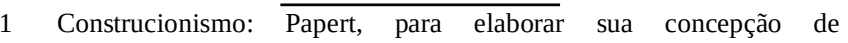
Construcionismo, aprofundou-se na Teoria Construtivista de Piaget e Vygotsky, mas acabou se distanciando da Psicologia do Desenvolvimento, passando a alinhavar uma teoria mais voltada para a intervenção pedagógica. Dessa forma, como o próprio Papert definiu, o Construcionismo passa a ser uma "reconstrução pessoal do construtivismo”(Silveira, 2012). 
múltiplas áreas do conhecimento.

Conforme Nérice (1978, p.284), metodologia pode ser compreendida como um "conjunto de procedimentos didáticos, representados por seus métodos e técnicas de ensino". Neste contexto são utilizados com o intuito de alcançar a máxima eficácia e rendimento no processo de ensino/aprendizagem, afirmam Brighenti et al (2015, p. 283).

Neste contexto as instituições escolares alicerçadas pelo Projeto Político Pedagógico procuram implementar todos os conhecimentos propostos nas matrizes curriculares. Contudo neste percurso há uma série de elementos pedagógicos, metodológicos e sociais que contrariam e inviabilizam a apropriação do conhecimento. Veiga em seu trabalho cita:

À medida que o ensino e a aprendizagem vieram, pouco a pouco, a se tornar escolares, com definições de conteúdos e currículos, ao lado da pedagogia e da didática, a educação também veio se tornando escolar, a ponto de a escola contemporaneamente constituir-se na forma educacional hegemônica. Se, antes, educação e escola se distinguiam pelas diferenças, em dias atuais se reúnem por uma preponderante identificação entre si (Veiga, 2013, p. 19)

Deste modo a implementação da tecnologia no processo de ensino aprendizagem é uma realidade necessária, visto que está posto nas diretrizes da BNCC Base Nacional Curricular Comum, indicando que a incorporação das novas tecnologias devem fundamentar e mediar transversalmente o processo de ensinoaprendizagem. De acordo com as orientações da BNCC as competências gerais da Educação Básica devem estar comprometidas com:

[Item 2 - Exercitar a curiosidade intelectual e recorrer à abordagem própria das ciências, incluindo a investigação, a reflexão, a análise crítica, a imaginação e a criatividade, para investigar causas, elaborar e testar hipóteses, formular e resolver problemas e criar soluções (inclusive tecnológicas) com base nos conhecimentos das diferentes áreas].[Item 5 - Compreender, utilizar e criar tecnologias digitais de informação e comunicação de forma crítica, significativa, reflexiva e ética nas diversas práticas sociais (incluindo as escolares) para se comunicar, acessar e disseminar informações, produzir conhecimentos, resolver problemas e exercer protagonismo e autoria na vida pessoal e coletiva](BNCC, 2017, p. 09).

\section{DESENVOLVIMENTO}

Em 2018 a Escola Municipal Anita Garibaldi recebeu uma oficina de Robótica Educacional promovida pela Secretária Municipal de Educação - SMED em parceria com a Fundação de Desenvolvimento e Tecnologia de Cascavel - Pr, FUNDETEC. Este evento contou com a participação de vários diretores de Escolas Municipais que apreciaram a proposta de implantação de um Projeto Piloto de Robótica Educacional. Dentre as Escolas participantes a Escola Municipal Anita Garibaldi localizada na sede do município acompanhada da Escola Municipal Washington Luiz do Distrito de Novo Sobradinho aderiram a proposição de utilizar a Robótica Educacional como elemento educativo nos seus espaços escolares.

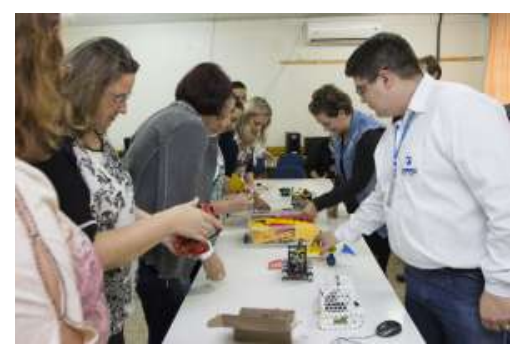

Fig. 1. Diretores de escolas participam de oficina de Robótica educacional. Fonte - Jornal do Oeste - Toledo - PR.

O Projeto Piloto de Robótica Educacional organizou seu atendimento no contra turno escolar para os alunos do $3^{\circ}$ ao $5^{\circ}$ ano do ensino fundamental $\mathrm{I}$, ao todo foram atendidos 240 alunos. Neste primeiro momento ocorreu no período de duas horas semanais em turmas com no máximo 15 alunos. Como proposta o trabalho educativo baseou-se nos conceitos básicos do pensamento computacional, cultura digital, tecnologia digital, lógica e atividades desplugadas. Importante destacar que o planejamento das atividades baseou-se no Currículo de Tecnologia e Computação - CIEB, o qual facilitou o trabalho com as habilidades educacionais previstas na BNCC.

Para dar suporte aos alunos, utilizou-se um kit proprietário de Robótica, nesta experiência optamos pelo material da ATTO o qual proporcionou condições de assimilação, compreensão e interação com as atividades propostas nas aulas de Robótica Educacional. Para Moran:

O professor se transforma agora no estimulador da curiosidade do aluno por querer conhecer, por pesquisar, por buscar a informação mais relevante. Num segundo momento, coordena o processo de apresentação dos resultados pelos alunos. Depois, questiona alguns dos dados apresentados, contextualiza os resultados, os adapta à realidade dos alunos, questiona os dados apresentados. Transforma informação em conhecimento e conhecimento em saber, em vida, em sabedoria, o conhecimento com ética (Moran, 1995, p.4).

Durante esta experiência observou-se que a mediação do professor é primordial para a construção e entendimento dos alunos. O professor neste mundo digital precisa orientar sobre a utilização correta dos meios tecnológicos e a significação do mesmo como ferramenta na aprendizagem nos espaços sociais intermediando a formação da cultura digital.

A ideia de que a tecnologia pode-se fazer tudo é perigosa, pois existem limites éticos e morais, ou seja, as 
práticas virtuais podem refletir consequências na vida real, por esse motivo deve-se instrumentalizar o aluno para que compreenda efetivamente que a tecnologia digital precisa ser usada como Solução e não tornar-se um problema. Portanto as ferramentas digitais fazem parte do cotidiano social e sua utilização necessita responsabilidade e cautela para que o resultado do uso tenha eficácia quanto a sua finalidade.

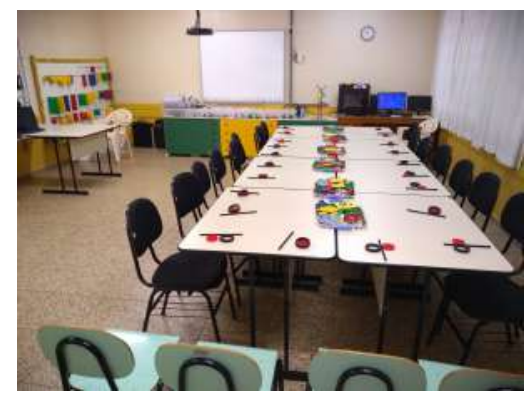

Fig. 2. Espaço Robótica Educacional, kit proprietário de Robótica ATTO. Fonte Arquivo EMAG.

Com o entusiasmo da experiência da Robótica Educacional em 2019 o projeto foi implementado e mudou seu formato para que pudesse atingir um maior número de alunos. Além do contra turno escolar para os alunos que já faziam parte do Projeto Piloto, ampliou-se as aulas de Robótica Educacional para todas as turmas do ensino Fundamental I. Assim semanalmente os alunos do PréEscolar ao $5^{\circ}$ ano participaram de uma aula de Robótica no período regular. Com a ampliação do atendimento, o acesso a Robótica Educacional passa de 240, para 480 alunos na faixa etária entre 04 a 12 anos.

Baseado na mediação do conhecimento, a proposta utilizou-se de grupos produtivos para desenvolvimento de Projetos Robóticos, esta dinâmica proporcionou a interação entre os alunos e possibilitou a interlocução e o protagonismo dos alunos no desenvolvimento dos desafios propostos. É de suma relevância ressaltar que as atividades encaminhadas pelo professor sempre estavam fundamentadas no Pensamento Computacional e relacionadas com os conteúdos curriculares, cuja sua importância deve ser considerada como um processo ativo de aplicação nas experiências realizadas na Robótica Educacional.

Para Papert (1994), a criatividade da criança associada a um objetivo pode promover organização e a construção de resultados práticos, é elementar a mediação do professor, para despertar o construcionismo.

\footnotetext{
as crianças farão melhor descobrindo ('pescando') por si mesmas o conhecimento específico de que precisam; a educação organizada ou informal poderá ajudar mais se certificar-se de que elas estarão sendo apoiadas moral, psicológica, material e intelectualmente em seus esforços. O tipo de conhecimento que as crianças mais precisam e o que as ajudará a obter mais conhecimento (PAPERT, 1994, p. 135).
}

Ainda em 2019 foi implementado o Projeto de Robótica Sustentável, considerando as possibilidades de acesso a Robótica a partir de materiais recicláveis utilizados no cotidiano social.

Neste experimento educativo os alunos propuseram-se a desenvolver protótipos Robóticos utilizando materiais sem custo, mais especificadamente a partir de lixo reciclável. Para isso tinham o suporte dos conhecimentos aprendidos nas aulas regulares de Robótica Educacional.

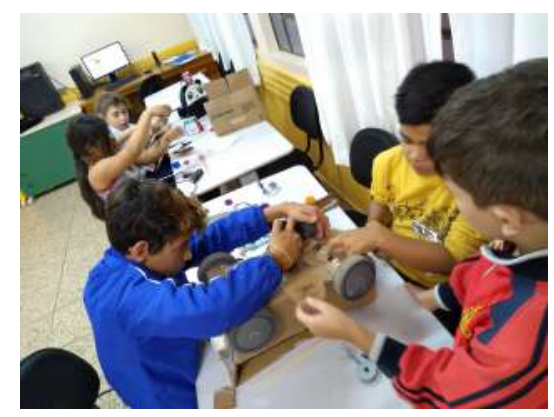

Fig. 3. Atividade de Robótica Sustentável. Fonte Arquivo EMAG.

\section{III. CONCLUSÃO}

A priori, muitos aspectos foram observados na execução do Projeto de Robótica Educacional na EMAG, no período de 2018 e 2019, mas o que chama atenção é o entusiasmo dos alunos quando tornam-se protagonistas da proposta educativa. O pensar, planejar, executar, calcular, ler, entender e compreender proporcionam ao aluno a participação ativa no processo de ensino-aprendizagem. A experiência com a Robótica Educacional demonstra a obrigatoriedade do professor ser o mediador para que os alunos percebam a necessidade e importância do conhecimento nas suas atividades sociais. Para Moran (1995) “A tecnologia deve servir para enriquecer o ambiente educacional, propiciando a construção de conhecimentos por meio de uma atuação ativa, crítica e criativa por parte de alunos e professores”.

O surpreendente neste processo foi que no desenvolver das atividades, os alunos internalizaram a importância da elaboração de grupos produtivos e de maneira autônoma e organizada desenvolveram seus protótipos, distribuindo as funções a cada participante e realizando com eficácia a resolução da proposta apresentada, utilizando do pensamento computacional e lógica mediadas pelo professor. Para Soffner:

Os processos educativos podem e devem ser contextualizados na sociedade da informação, utilizando os diversos recursos que as novas tecnologias possibilitam no âmbito educacional, seja na educação formal representada pela escola, seja na educação do meio sociocomunitário. Independentemente do lugar onde $\mathrm{o}$ aprendizado acontece, seja no meio formal ou não formal, cremos que esta construção do conhecimento mediada pelo educador pode e deve contar com as tecnologias para 
ampliar as possibilidades de comunicação e interação (Soffner, 2013 p. 158).

Pode-se considerar que no espaço escolar a utilização das novas tecnologias devem ser encaradas como uma ferramenta de aproximação do aluno com a aprendizagem. É de extrema necessidade pensar metodologias que aproveitem os conteúdos transversais escolares e conectá-los as novas realidades digitais, essa pode ser uma oportunidade de promoção da ação educativa.

A tecnologia cria um ambiente que desperta o interesse do aluno para outras formas do aprender e oportuniza um espaço pedagógico de produção do conhecimento tornando aluno ativo no processo. $\mathrm{O}$ professor deve aproveitar o suporte que os recursos tecnológicos digitais oferecem ao campo escolar para mediar a aprendizagem, assim como a escola não pode ser excludente, precisa garantir uma linguagem que atinja os alunos, que provoque sua aproximação com o conhecimento, e proporcione o desenvolvimento do aluno no processo de desenvolvimento da aprendizagem e da formação humana.

Segundo o pensamento de Paulo Freire (1996, p. 52) é necessário "saber que ensinar não é transferir conhecimento, mas criar as possibilidades para sua própria produção ou a sua construção”.

A Robótica educacional conforme a experiência apresentada neste trabalho pode proporcionar e flexibilizar a implementação dos Currículos Escolares e múltiplas aprendizagens, isso porque é uma ferramenta que proporciona subsídios para mediar a ação educativa dentro da Escola, ampliando a possibilidade da formação de um aluno ativo e pesquisador. O professor deve compreender que a mediação do conhecimento é um processo que humaniza, a interação professor/aluno considera o conhecimento de ambos os envolvidos.

Para finalizar, Papert não discute qual a melhor teoria da aprendizagem, mas utiliza elementos do construtivismo e da psicologia do desenvolvimento para formular o construcionismo que considera uma evolução metodológica no ensino. A ação mediadora do professor aliado a utilização da tecnologia fazem a diferença para a promoção do conhecimento sistematizado.

Qualquer situação de aprendizado com a qual a criança se defronta na escola tem sempre uma história prévia. Por exemplo, as crianças começam a estudar aritmética na escola, mas muito antes elas tiveram alguma experiência com quantidades elas tiveram que lidar com operações de divisão, adição, subtração, e determinação de tamanho. Consequentemente, as crianças têm a sua própria aritmética préescolar, que somente psicólogos míopes podem ignorar. Continua-se afirmando que o aprendizado tal como ocorre na idade pré-escolar difere nitidamente do aprendizado escolar, o qual está voltado para a assimilação de fundamentos do conhecimento científico. No entanto, já no período de suas primeiras perguntas, quando a criança assimila os nomes de objetos em seu ambiente, ela está aprendendo (VYGOTSKI, 1991, p. 94-95).

\section{AgradeCimentos}

SMED - Secretaria Municipal de Educação de Toledo - Pr.

NITE - Nucleo de Inovações e Tecnologia Educacionais.

FAG - Faculdade Assis Gurgacz - Campus Toledo - Pr.

EMAG - Escola Municipal Anita Garibaldi - Toledo - Pr.

\section{REFERÊNCIAS}

[1] BRASIL. Base Nacional Curricular Comum. MEC Disponível: http://basenacionalcomum.mec.gov.br/images/BNCC_EI_EF_110518 versaofinal_site.pdf

[2] BRIGHENTI, Josiane.; BIAVATTI, Vania Tanira.; SOUZA, Taciana Rodrigues de. Metodologias de ensino-aprendizagem: uma abordagem sob a percepção dos alunos. Disponível: https://periodicos.ufsc.br/index.php/gual/article/view/1983$35.2015 \mathrm{v} 8 \mathrm{n} 3 \mathrm{p} 281$

[3] FREIRE, Paulo. Pedagogia da Autonomia. Saberes Necessários à prática educativa. São Paulo, Paz e Terra, 1996.

[3] FRAWLEY, Willian.Vigotsky e a ciência cognitiva: linguagem das mentes social e computacional. Porto Alegre: Artes Médicas Sul, 2000.

[4] HERNÁNDEZ, Fernando.; VENTURA, Montserrat. A organização do currículo por projeto de trabalho: o conhecimento é um caleidoscópio. Porto Alegre: Artmed, 1998.

[5] HERNÁNDEZ, Fernando.Transgressão e mudança na educação: os projetos de trabalho. Porto Alegre: Artmed, 1998.

[6] LITWIN, Edith. Tecnologia educacional: Política, histórias e propostas. Porto Alegre: Artmed, 1997.

[7] MORAN, José Manuel. Novas tecnologias e o reencantamento do mundo. Revista Tecnologia Educacional. Rio de Janeiro, vol. 23, n2.126, set. / out. 1995 .

[8] NÉRICI, Imideo Giuseppe. Didática geral dinâmica. 9.ed. São Paulo: Atlas,1978.

[9] PAPERT, Seymour M. A Máquina das Crianças: Repensando a Escola na Era da Informática. Porto Alegre, Artes Médicas, 1994.

[10] PIAGET, Jean. Seis Estudos de Psicologia. Rio de Janeiro: Forense Universitária, 1998.

[11]REPORTAGEM. Jornal do Oeste 09/07/2019. "Robótica educacional: projeto visa melhorar qualidade de ensino nas escolas". Disponivel em:https:/www.jornaldooeste.com.br/noticia/robotica-educacionalprojeto-visa-melhorar-qualidade-de-ensino-nas-escolas

[12] SOFFNER, Renato. Tecnologia e Educação: Um diálogo Freire Papert. Centro de Educação - UFPE, 2013.

[13] VEIGA, Alencastro. Novas tramas para as técnicas de ensino e estudo. Ilma Passos, Campinas, SP: Papirus, 2013.

[14] VYGOTSKI, Lev Semyonovich. A formação social da mente. $4^{\circ}$ ed. Trad. José Cipolla Neto, Luís Silveira Menna Barreto e Solange Castro Afeche. São Paulo: Martins Fontes,1991. 